\title{
Interaction of Mouse Macrophage Elastase with Native and Oxidized Human $\alpha_{1}$-Proteinase Inhibitor
}

\author{
Michael J. Banda,* Elizabeth J. Clark, " Sukanto Sinha," and James Travis ${ }^{\ddagger}$ \\ *Laboratory of Radiobiology and Environmental Health, University of California at San Francisco, San Francisco, California 94143; and \\ ${ }^{\ddagger}$ Department of Biochemistry, University of Georgia, Athens, Georgia 30602
}

\begin{abstract}
Native and oxidized $\alpha_{1}$-proteinase inhibitor ( $\alpha_{1}-$ PI) were compared as substrates for the metalloproteinase macrophage elastase. At substrate concentrations at which native $\alpha_{1}$-PI was readily degraded by macrophage elastase, oxidized $\alpha_{1}$-PI was hardly degraded at all. Incubation of macrophage elastase with oxidized $\alpha_{1}$-PI before the addition of native $\alpha_{1}$-PI showed that oxidized $\alpha_{1}-\mathrm{PI}$ was not an inhibitor of macrophage elastase. Competition experiments with up to twofold excess oxidized $\alpha_{1}$ PI did not interfere with the degradation of native $\alpha_{1}$-PI by macrophage elastase. Sequence analysis of amino acids in degraded native $\alpha_{\mathbf{1}}$-PI showed that macrophage elastase attacked a single peptide bond between Pro-357 and Met-358, the latter representing the $P_{1}$ reactive-site residue of $\alpha_{1}-$ PI. In oxidized $\alpha_{1}-$ PI, Met-358 was converted to methionine sulfoxide and macrophage elastase hydrolyzed the bond between Phe-352 and Leu-353. These data suggest that methionine may be the primary cleavage site for macrophage elastase and not leucine, as previously thought.
\end{abstract}

\section{Introduction}

The extracellular elastin matrix is protected from degradation by granulocyte elastase by a critical balance of this serine proteinase (1-3) and its major inhibitor, $\alpha_{1}$-proteinase inhibitor $\left(\alpha_{1^{-}}\right.$ PI) ${ }^{1}$ (4). It has been suggested that a disruption of this balance in favor of the proteinase will predispose an individual to degenerative lung diseases (4-6). Previous studies on the interaction of inflammatory macrophages with $\alpha_{1}$-PI have shown that macrophage elastase, a secreted metalloproteinase, can disrupt the balance between granulocyte elastase and $\alpha_{1}$-PI by proteolytic inactivation of $\alpha_{1}-\mathrm{PI}(7,8)$. Proteolysis by macrophage elastase reduces the molecular weight of $\alpha_{1}$-PI by 4,000 , without the formation of a stable macrophage elastase- $\alpha_{1}$-PI inhibitory complex.

Oxidation of the reactive-site methionine residue is an important means of inactivating $\alpha_{1}$-PI (9) because the oxidized form of $\alpha_{1}$-PI is slow in forming an inhibitory complex with granulocyte elastase. As a result, oxidized $\alpha_{1}$-PI becomes sus-

Dr. Sinha's present address is Department of Pharmacological Science, School of Medicine, Health Science Center, SUNY at Stony Brook, Stony Brook, NY 11794. Address correspondence to Dr. Banda.

Received for publication 1 October 1986.

1. Abbreviations used in this paper: $\alpha_{1}-\mathrm{PI}, \alpha_{1}$-proteinase inhibitor, PTH, parathyroid hormone.

J. Clin. Invest.

(c) The American Society for Clinical Investigation, Inc.

0021-9738/87/05/1314/04 \$1.00

Volume 79, May 1987, 1314-1317 ceptible to proteolysis by granulocyte elastase and by other serine proteinases it would normally inhibit.

In this study we determined the relative susceptibility of native and oxidized $\alpha_{1}$-PI to degradation by macrophage elastase. Because the proteolysis of native $\alpha_{1}$-PI by macrophage elastase may be limited to one or a very few sites, we also identified the cleavage sites.

\section{Methods}

Macrophage elastase. Mouse macrophage elastase was purified from culture medium conditioned by thioglycollate-elicited mouse peritoneal macrophages (10). Elastinolytic activity was determined using an insoluble $\left[{ }^{3} \mathrm{H}\right]$ elastin substrate $(10)$.

$\alpha_{1}-P I$. Human $\alpha_{1}$-PI was either used directly as purchased from Calbiochem-Behring Corp. (San Diego, CA) or repurified after purchase from Sigma Chemical Co. (St. Louis, MO). The principal contaminant was albumin. Repurification was achieved by fractionation on a Cibracon Blue-CL-6-Sepharose column equilibrated with a buffer consisting of 50 $\mathrm{mM}$ Tris- $\mathrm{HCl}, \mathrm{pH} 8.5$, and $0.01 \% \mathrm{NaN}_{3}(11)$.

Iodination. Homogeneous $\alpha_{1}$-PI was radioiodinated by the method of Bolton and Hunter (12). In this method the lysine residues are labeled, thus avoiding the inactivation of $\alpha_{1}-\mathrm{PI}$ by oxidation of methionine that would result from use of the chloramine-T iodination procedure. ${ }^{125} \mathrm{I}$ Labeled Bolton-Hunter reagent was purchased from New England Nuclear (Boston, MA). The specific activity of ${ }^{125}$ I-labeled $\alpha_{1}-$ PI varied from 0.1 to $0.2 \mu \mathrm{Ci} / \mathrm{nmol}$.

Cell-free oxidation of $\alpha_{1}-P I$. Oxidized $\alpha_{1}$-PI was prepared by mixing native $\alpha_{1}$-PI with a 20 -fold molar excess of $N$-chlorosuccinimide (Sigma Chemical Co.). The mixture was incubated at ambient temperature for $20 \mathrm{~min}$, and the reaction was stopped by the addition of $120 \mathrm{~mol}$ of methionine per mole of $\alpha_{1}$-PI. Sham-oxidized $\alpha_{1}$-PI was prepared similarly except that the $N$-chlorosuccinimide and methionine were combined and then added to $\alpha_{1}$-PI before the 20-min incubation. The inhibitory capacity of the oxidized $\alpha_{1}$-PI was measured by determining the activity of pancreatic elastase remaining after incubation for $15 \mathrm{~min}$ with the oxidized $\alpha_{1}-$ PI. Activity was determined by measuring the rate of cleavage of succinyl-trialanyl-paranitroanalide (13).

Proteolysis of $\alpha_{l}$-PI by macrophage elastase. Reaction mixtures containing macrophage elastase and either native or oxidized $\alpha_{1}$-PI (1:100 $\mathrm{wt} / \mathrm{wt}$ ) were incubated at $37^{\circ} \mathrm{C}$ in a buffer consisting of $50 \mathrm{mM}$ Tris$\mathrm{HCl}, 50 \mathrm{mM} \mathrm{NaCl}$, and $10 \mathrm{mM} \mathrm{CaCl}_{2}, \mathrm{pH} 8.0$, for $1-15 \mathrm{~h}$ before the addition of sufficient EDTA to give a final concentration of $20 \mathrm{mM}$. Inhibition studies were carried out by preincubating macrophage elastase with up to a tenfold molar excess of oxidized $\alpha_{1}-\mathrm{PI}$ for $30 \mathrm{~min}$. Radiolabeled native $\alpha_{1}$-PI was then added to determine if macrophage elastase could still cleave it. In competition studies, the concentration of ${ }^{125} \mathrm{I}$ labeled native $\alpha_{1}$-PI was held constant while the concentration of nonradiolabeled oxidized $\alpha_{1}$-PI was increased. The ratio of native to oxidized $\alpha_{1}-\mathrm{PI}$ varied from 1:0.1 to 1:2. Sufficient amounts of proteolyzed $\alpha_{1}-\mathrm{PI}$ for sequence analysis were obtained by incubating either native or oxidized $\alpha_{1}$-PI at $53 \mu \mathrm{M}$ with $0.13 \mu \mathrm{M}$ macrophage elastase at $37^{\circ} \mathrm{C}$. Additional $\alpha_{1}$-PI was added every $30 \mathrm{~min}$ for the next $2 \mathrm{~h}$, giving a final concentration of $65 \mu \mathrm{M}$. The final ratio of enzyme to substrate was 1: $500(\mathrm{~mol} / \mathrm{mol})$. By this strategy we maintained an optimal cleavage rate of $\alpha_{1}$-PI without increasing the concentration of macrophage elastase. 
After incubation, the final mixture was diluted to $5 \mathrm{ml}$ with water, dialyzed against water, and lyophilized before sequence analysis.

Electrophoresis. Sodium dodecyl sulfate (SDS)-polyacrylamide gradient gel electrophoresis was performed according to the method of Laemmli (14) as modified (7). After electrophoresis the protein bands were stained with $0.05 \%$ (vol/vol) Coomassie Blue R250 in methanol. Radiolabeled proteins were located by autoradiography on Kodak X-Omat $\mathbf{R}$ x-ray film (15).

Sequence analysis. Proteolyzed samples of native and oxidized $\alpha_{1}$ PI (28-30 nmol) were sequenced with a Beckman $890 \mathrm{C}$ spinning-cup sequenator. Usually, ten cycles were carried out for each sample. The individual fractions were converted to stable parathyroid hormone (PTH) amino acids manually (16), and 5\% of each fraction was analyzed for 15 min isocratically on a DuPont Zorbax-ODS high-pressure liquid chromatography column in $6 \mathrm{mM} \mathrm{NaOAc}, \mathrm{pH} 4.5$, with $42 \%$ acetonitrile. The PTH amino acids were detected at $254 \mathrm{~nm}$, except for PTH-Ser and PTH-Thr, which were detected at $313 \mathrm{~nm}$. Residues that could not be unequivocally identified were confirmed by back-hydrolysis of the PTH derivative (17), followed by amino acid analysis. The following protein samples were analyzed by this procedure: $(a)$ native $\alpha_{1}$-PI; $(b)$ native $\alpha_{1}$ PI cleaved by macrophage elastase; (c) oxidized $\alpha_{1}-\mathrm{PI}$; and $(d)$ oxidized $\alpha_{1}$-PI cleaved by macrophage elastase. Samples $(a)$ and $(d)$ were prepared twice with different ratios of proteinase to substrate, and each sample was analyzed separately.

\section{Results}

Comparison of native and oxidized $\alpha_{1}$-PI as substrates for macrophage elastase. Because our previous studies were limited to studying the interaction of mouse peritoneal macrophage elastase and rabbit alveolar macrophages with native $\alpha_{1}$-PI $(7,8)$, we have investigated the interaction of purified mouse peritoneal macrophage elastase with oxidized $\alpha_{1}$-PI. To determine their relative sensitivity to proteolysis by macrophage elastase, we carried out separate reactions with native and oxidized $\alpha_{1}$-PI. In each case the ratio of macrophage elastase to $\alpha_{1}$-PI was 1:40 ( $\mathrm{mol} / \mathrm{mol}$ ). Under these conditions, native $\alpha_{1}$-PI was readily degraded, whereas oxidized $\alpha_{1}$-PI was degraded only slightly (Fig. 1). Reaction mixtures containing sham-oxidized $\alpha_{1}$-PI appeared to be identical to those containing native $\alpha_{1}$-PI. Therefore, oxidized $\alpha_{1}$-PI was a comparatively poor substrate for macrophage elastase.

Potential inhibition of macrophage elastase by oxidized $\alpha_{1^{-}}$ $P I$. The inability of macrophage elastase to degrade oxidized $\alpha_{1^{-}}$ PI could be due to an inhibitory effect of oxidized $\alpha_{1}$-PI on

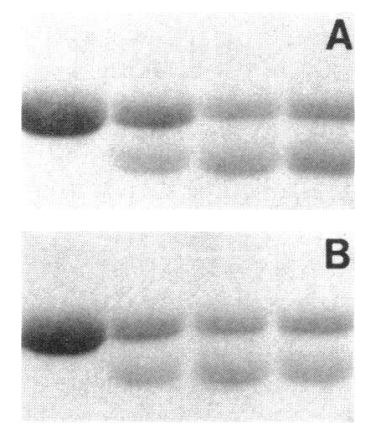

Figure 1. Proteolysis of $(A)$ native $\alpha_{1-}$ PI, $(B)$ sham-oxidized $\alpha_{1}-\mathrm{PI}$, and $(C)$ oxidized $\alpha_{1}$-PI, analyzed on SDSpolyacrylamide electrophoretic gels. (a) $\alpha_{1}-\mathrm{PI}$ incubated for $15 \mathrm{~h}$ at $37^{\circ} \mathrm{C}$ without macrophage elastase; $(b-d)$ reaction mixtures containing macrophage elastase and $\alpha_{1}$-PI (1:40 mol: mol) incubated at $37^{\circ} \mathrm{C}$ for $(b) 1 \mathrm{~h},(c)$

$5 \mathrm{~h}$, or $(d) 15 \mathrm{~h}$.

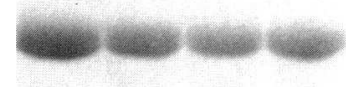

a b c

d macrophage elastase. To examine this possibility, we carried out two experiments. In the first, 2 pmol of macrophage elastase was incubated for $30 \mathrm{~min}$ at ambient temperature with up to $20 \mathrm{pmol}$ of oxidized $\alpha_{1}$-PI before incubation with $74 \mathrm{pmol}$ of ${ }^{125} \mathrm{I}$-labeled native $\alpha_{1}$-PI. When the reaction mixtures were analyzed by SDS-polyacrylamide gel electrophoresis, there was no inhibition of the proteolysis of native $\alpha_{1}$-PI (Fig. 2). To determine if oxidized $\alpha_{1}$-PI might act as a competitive inhibitor, increasing amounts of oxidized $\alpha_{1}$-PI were mixed with fixed amounts of ${ }^{125} \mathrm{I}$-labeled native $\alpha_{1}$-PI and macrophage elastase. The ratio of native to oxidized $\alpha_{1}$-PI varied from 1:0.1 to 1:2. When these reaction mixtures were analyzed by SDS-polyacrylamide gel electrophoresis, there was no interference with the proteolysis of native $\alpha_{1}$-PI (Fig. 3). These data suggest that oxidized $\alpha_{1}$-PI is not an effective inhibitor of macrophage elastase.

Analysis of the cleavage site in $\alpha_{1}-P I$. The limited proteolysis of native $\alpha_{1}$-PI by macrophage elastase always resulted in a reduction of the molecular weight of $\alpha_{1}$-PI by 4,000 without the formation of any other intermediate-sized fragments. This suggested that macrophage elastase cleaves $\alpha_{1}$-PI at only one site. As shown in Table I and Fig. 4, data from sequence analysis indicated two $\mathrm{NH}_{2}$-terminals. After eliminating the known $\alpha_{1}$ PI $\mathrm{NH}_{2}$-terminal sequence, it is evident that the other sequence must have been generated by cleavage between Pro-357 and Met-358, the reactive-site $P_{1}$ residue. According to the known amino acid sequence of $\alpha_{1}$-PI, a cleavage at this site would remove a fragment with a molecular weight of 4,200 . This compares favorably with our estimate, based on migration in SDSpolyacrylamide gels, of a reduction in molecular weight of 4,000 .

In $\alpha_{1}$-PI that has been inactivated by oxidation, the reactivesite residue Met-358 is converted to methionine sulfoxide (9). It is likely that methionine sulfoxide interferes with the binding of macrophage elastase to oxidized $\alpha_{1}$-PI, and thus retards the cleavage amino to methionine sulfoxide-358. As noted in Fig. 1 , there was slight proteolysis of oxidized $\alpha_{1}-\mathrm{PI}$. By increasing the concentration of oxidized $\alpha_{1}$-PI without increasing the concentration of macrophage elastase, a sufficient amount of the oxidized cleavage fragment was accumulated to permit sequence analysis. There was no cleavage at methionine sulfoxide- 358 . Rather, the bond between Phe-352 and Leu-353 was cleaved (Table I and Fig. 4). Because oxidized $\alpha_{1}$-PI is not as readily proteolyzed as native $\alpha_{1}$-PI, the cleavage amino to Leu-353 is

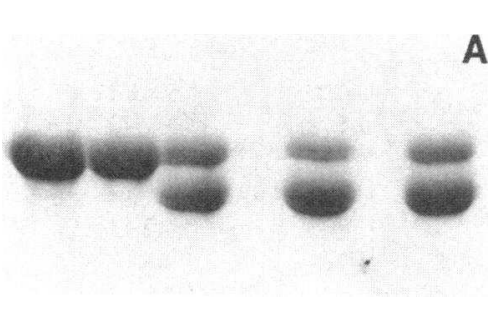

A

2. Effect of oxi-

dized $\alpha_{1}$-PI on the activity of macrophage elastase. $(A)$ Coomassie Blue staining for total protein. (B) Autoradiograph of ${ }^{125}$ I-labeled native $\alpha_{1}$ PI only. Various amounts of nonradiolabeled oxidized $\alpha_{1}$-PI were incubated for 30 min with macrophage elastase before the addition of 74 pmol of ${ }^{125} \mathrm{I}$ labeled native $\alpha_{1}-\mathrm{PI}$, incubation at $37^{\circ} \mathrm{C}$ for 5 $h$, and analysis on SDSpolyacrylamide gels. The final ratios of macrophage elastase to oxidized $\alpha_{1}$-PI to ${ }^{125} \mathrm{I}$-labeled native $\alpha_{1}$-PI (mole/mole/mole) were (a) 0:0: 74, (b) 0:2:74, (c) 2:0:74, (d) 2:1:74, and (e) 2:20:74. 


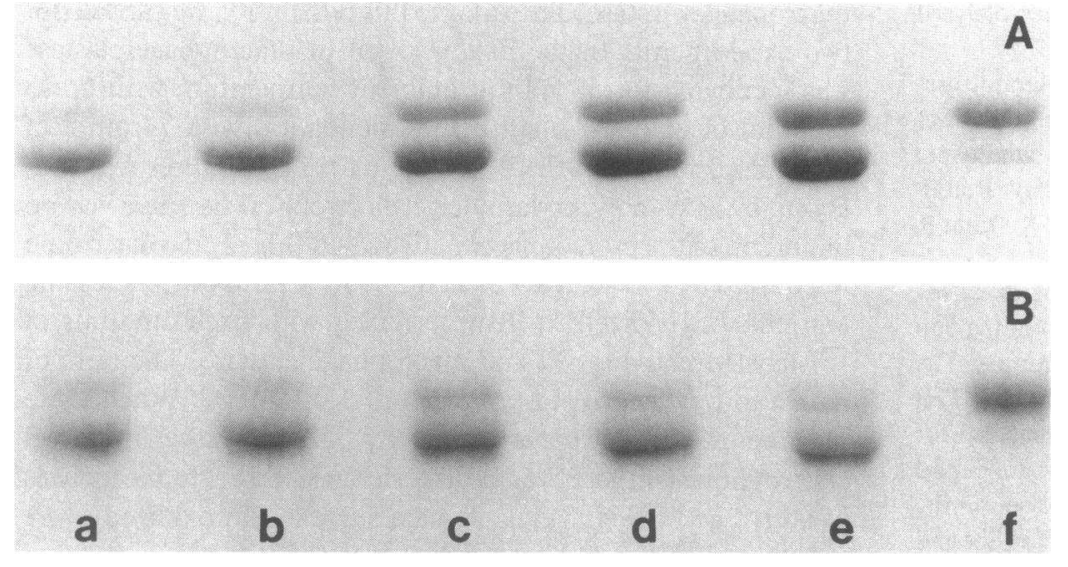

Figure 3. Oxidized $\alpha_{1}$-PI as a competitive substrate for macrophage elastase. $(A)$ Coomassie Blue staining for total protein. (B) Autoradiograph of the ${ }^{125}$ I-labeled native $\alpha_{1}$-PI only. SDS-polyacrylamide gels contained reaction mixtures in which the amounts of macrophage elastase ( $1 \mathrm{pmol})$ and native $\alpha_{1}$-PI ( $\left.37 \mathrm{pmol}\right)$ were held constant and the amount of oxidized $\alpha_{1}$-PI was varied from 0 to $74 \mathrm{pmol}$. The ratios of ${ }^{125} \mathrm{I}-\mathrm{la}$ beled native $\alpha_{1}$-PI to oxidized $\alpha_{1}$-PI in each lane were (a) 1:0, (b) 1:0.1, (c) 1:0.5, (d) 1:1, and (e) 1:2. (f) 37 pmol of native $\alpha_{1}$-PI incubated without macrophage elastase. probably a secondary site that would not normally be cleaved at lower substrate concentrations or when the Met-358 site is open. Cleavage at the Leu-353 site would result in a reduction of the molecular weight of the oxidized $\alpha_{1}$-PI by 4,500 . It is unlikely that the difference between the 4,200-mol-wt fragment of native $\alpha_{1}$-PI and the 4,500-mol-wt fragment of oxidized $\alpha_{1^{-}}$ PI would be detected on SDS-polyacrylamide electrophoretic gels.

\section{Discussion}

The proteolysis of $\alpha_{1}$-PI by macrophage elastase is based on the recognition of the reactive-site residue Met-358. That this is the preferred site for macrophage elastase binding in the native molecule explains the poor interaction of macrophage elastase with oxidized $\alpha_{1}$-PI. Presumably, the conversion of Met-358 to methionine sulfoxide after oxidation prevents macrophage elastase from binding and cleaving at that site. Our data show that oxidized $\alpha_{1}$-PI does not interfere with the proteolysis of native $\alpha_{1-}$ PI by serving as a competitive inhibitor.

The residue recognized by metalloproteinases contributes the amino group to the peptide bond that is cleaved $(10,18)$, which is why macrophage elastase, a metalloproteinase, recog-

Table I. Sequence Analysis of Native and Oxidized $\alpha_{1}-P I$ before and after Degradation by Macrophage Elastase

\begin{tabular}{rllll}
\hline & Amino acids encountered & & \\
\cline { 2 - 5 } Step & Native $\alpha_{1}$-PI & Oxidized $\alpha_{1}$-PI & $\begin{array}{l}\text { Native } \alpha_{1} \text {-PI } \\
\text { degraded by } \\
\text { macrophage elastase }\end{array}$ & $\begin{array}{l}\text { Oxidized } \alpha_{1} \text {-PI } \\
\text { degraded by } \\
\text { macrophage elastase }\end{array}$ \\
\hline 1 & Glu & Glu & Glu, Met & Glu, Leu \\
2 & Asp & Asp & Asp, Ser & Asp, Glu \\
3 & Pro & Pro & Pro, lle & Pro, Ala \\
4 & Gln & Gln & Gln, Pro & Gln, Ile \\
5 & Gly & Gly & Gly, Pro & Gly, Pro \\
6 & Asp & Asp & Asp, Glu & Asp, Met \\
7 & Ala & Ala & Ala, Val & Ala, Ser \\
8 & Ala & Ala & Ala, Lys & Ala, Ile \\
9 & Gln & Gln & Gln, Phe & Gln, Pro \\
10 & Lys & Lys & Lys, Asn & Lys, Pro \\
\end{tabular}

Using the yields at steps 4 and 9 (Gln) of undegraded native $\alpha_{1}$-PI, a low repetitive yield of $89 \%$ was calculated.

nizes Met-358 rather than Pro-357. We were surprised that this bond was the primary cleavage site because previous work showed that macrophage elastase cleaved the peptide bond amino to leucine and isoleucine residues $(10,18)$. However, those studies were done using elastin (10) and insulin B-chain (18) as substrates, neither of which contains methionine residues. The data presented here suggest that leucine may be a secondary cleavage site and that methionine may be the primary site. That macrophage elastase does not degrade elastin as effectively as the serine elastases may be due to the lack of primary cleavage sites (i.e., methionine) for macrophage elastase in elastin.

Other proteinases besides macrophage elastase degrade $\alpha_{1}$ PI (19-23). Papain and some serine proteinases cleave the peptide bond between Met-358 and Ser-359 (24). Pseudomonas aeruginosa elastase, also a metalloproteinase, cleaves the same bond as macrophage elastase (25), while another metalloproteinase from the venom of Crotalus adamanteus recognizes Met-351 and cleaves the Met-351-Ala-350 bond while leaving the Met358-Pro-357 bond intact (26). That the peptide bonds amino to Met-351 and Met-358 are cleaved by different proteinases is evidence that both sites are normally available for proteolysis. The specificity of macrophage elastase for Met-358 rather than Met-351 may be due to the Ala-Ala-Gly-Ala sequence (residues 347-350) immediately preceding Met-351 (Fig. 4). Because macrophage elastase does not cleave alanine-rich peptide substrates $(10,27)$, these nonpolar amino acid residues may prevent macrophage elastase from recognizing Met-351.

Tissue metalloproteinases may play an important role in the turnover of connective tissue. Metalloelastase activity has been identified in the secretions of cultured human alveolar macrophages (28) and in human lung lavage fluid (29). In both cases these elastase activities were not inhibited by $\alpha_{1}-\mathrm{PI}$, and in one study (29) it was suggested that elevated elastase concentrations decreased the concentration of antigenic $\alpha_{1}$-PI. The secretion of

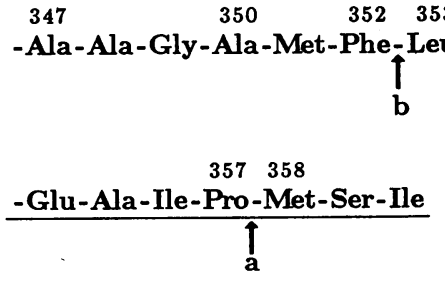

367

-Pro-Pro-Glu-Val -Lys-Phe-Asn
Figure 4. Partial sequence of $\alpha_{1}-\mathrm{PI}$. The underlined residues constitute the active site of $\alpha_{1}$-PI. The peptide bonds cleaved by macrophage elastase are indicated for native $\alpha_{1}-\mathrm{PI}$ (arrow $a$ ) and oxidized $\alpha_{1}$ PI (arrow b). 
elastase by rabbit alveolar macrophages in culture was correlated with the proteolytic inactivation of $\alpha_{1}$-PI (8). It is possible that other tissue metalloproteinases besides macrophage elastase may also degrade and inactivate $\alpha_{1}$-PI (30). In certain pathologic conditions, exogenous metalloproteinases can inactivate $\alpha_{1}$-PI (20-23) and other proteinase inhibitors (31). Therefore, tissue metalloproteinases and exogenous metalloproteinases must be considered regulatory variables that could disrupt the balance between serine proteinases and proteinase inhibitors in vivo.

More intriguing is the possibility that oxidation of $\alpha_{1}$-PI may, in some circumstances, play a protective role by preventing degradation of $\alpha_{1}$-PI by metalloproteinases such as macrophage elastase. For example, although proteolysis causes irreversible inactivation of $\alpha_{1}$-PI, oxidation can theoretically be reversed by an endogenous reductive mechanism (32). If this were shown to be the case in vivo, then one advantage in having methionine as the reactive-site residue of $\alpha_{1}$-PI would be to avoid proteolysis.

\section{Acknowledgments}

This work was supported by National Institutes of Health grants HL26323 and AM32746, and by contract DE-AC03-76-SF01012 from the Office of Health and Environmental Research, U. S. Department of Energy.

\section{References}

1. Ohlsson, K., and I. Olsson. 1974. The neutral proteases of human granulocytes: isolation and partial characterization of granulocyte elastases. Eur. J. Biochem. 42:519-527.

2. Baugh, R. J., and J. Travis. 1976. Human leukocyte granule elastase: rapid isolation and characterization. Biochemistry. 15:836-841.

3. Starkey, P. M., and A. J. Barrett. 1976. Human lysosomal elastase: catalytic and immunological properties. Biochem. J. 155:265-271.

4. Travis, J., and G. S. Salvesen. 1983. Human plasma proteinase inhibitors. Annu. Rev. Biochem. 52:655-709.

5. Bignon, J., and G. L. Scarpa, editors. 1980. Clinical respiratory physiology. 3B. Alpha 1 -proteinase inhibitor. Bull. Eur. Physiopathol. Respir. 16(Suppl.):285-353.

6. Harpel, P. C. 1983. Protease inhibitors: a precarious balance. $N$. Engl. J. Med. 309:725-726.

7. Banda, M. J., E. J. Clark, and Z. Werb. 1980. Limited proteolysis by macrophage elastase inactivates human $\alpha_{1}$-proteinase inhibitor. $J$. Exp. Med. 152:1563-1570.

8. Banda, M. J., E. J. Clark, and Z. Werb. 1985. Regulation of alpha proteinase inhibitor function by rabbit alveolar macrophages. Evidence for proteolytic rather than oxidative inactivation. J. Clin. Invest. 75: 1758-1762.

9. Johnson, D., and J. Travis. 1979. The oxidative inactivation of human $\alpha$-1-proteinase inhibitor. Further evidence for methionine at the reactive center. J. Biol. Chem. 254:4022-4026.

10. Banda, M. J., and Z. Werb. 1981. Mouse macrophage elastase: Purification and characterization as a metalloproteinase. Biochem. $J$. 193:589-605.

11. Travis, J., J. Bowen, D. Tewksbury, D. Johnson, and R. Pannell. 1976. Isolation of albumin from whole human plasma and fractionation of albumin-depleted plasma. Biochem. J. 157:301-306.

12. Bolton, A. E., and W. M. Hunter. 1973. The labelling of proteins to high specific radioactivities by conjugation to ${ }^{125}$ I-containing acylating agent. Application to the radioimmunoassay. Biochem. J. 133:529-539.
13. Bieth, J., B. Spiess, and C. G. Wermuth. 1974. The synthesis and analytical use of a highly sensitive and convenient substrate of elastase. Biochem. Med. 11:350-357.

14. Laemmli, U. K. 1970. Cleavage of structural proteins during the assembly of the head of bacteriophage T4. Nature (Lond.). 227:680-685.

15. Laskey, R. A., and A. D. Mills. 1975. Quantitative film detection of ${ }^{3} \mathrm{H}$ and ${ }^{14} \mathrm{C}$ in polyacrylamide gels by fluorography. Eur. J. Biochem. $56: 335-341$.

16. Edman, P., and G. Begg. 1967. A protein sequenator. Eur. J. Biochem. 1:80-91.

17. Mendez, E., and C. Y. Lai. 1975. Regeneration of amino acids from thiazolinones formed in the Edman degradation. Anal. Biochem. 68:47-53.

18. Kettner, C., E. Shaw, R. White, and A. Janoff. 1981. The specificity of macrophage elastase on the insulin B-chain. Biochem. J. 195:369372.

19. Johnson, D., and J. Travis. 1977. Inactivation of human $\alpha_{1}$ proteinase inhibitor by thiol proteinases. Biochem. J. 163:639-641.

20. Moskowitz, R. W., and G. Heinrich. 1971. Bacterial inactivation of human serum alpha-1 antitrypsin. J. Lab. Clin. Med. 77:777-785.

21. Morihara, K., H. Tsuzuki, and K. Oda. 1979. Protease and elastase of Pseudomonas aeruginosa: Inactivation of human plasma $\alpha_{1}$-proteinase inhibitor. Infect. Immun. 24:188-193.

22. Kurecki, T., M. Laskowski, Sr., and L. F. Kress. 1978. Purification and some properties of two proteinases from Crotalus adamanteus venom that inactivate human $\alpha_{1}$-proteinase inhibitor. J. Biol. Chem. 253:83408345.

23. Kress, L. F., and E. A. Paroski. 1978. Enzymatic inactivation of human serum proteinase inhibitors by snake venom proteinases. Biochem. Biophys. Res. Commun. 83:649-656.

24. Morihara, K., H. Tsuzuki, M. Harada, and T. Iwata. 1984. Purification of human plasma $\alpha_{1}$-proteinase inhibitor and its inactivation by Pseudomonas aeruginosa elastase. J. Biochem. 95:795-804.

25. Johnson, D., and J. Travis. 1978. Structural evidence for methionine at the reactive site of human $\alpha$-1-proteinase inhibitor. J. Biol. Chem. 253:7142-7144.

26. Kress, L. F., T. Kurecki, S. K. Chan, and M. Laskowski, Sr. 1979. Characterization of the inactive fragment resulting from limited proteolysis of human $\alpha_{1}$-proteinase inhibitor by Crotalus adamanteus proteinase II. J. Biol. Chem. 254:5317-5320.

27. White, R. R., D. Norby, A. Janoff, and R. Dearing. 1980. Partial purification and characterization of mouse peritoneal exudative macrophage elastase. Biochim. Biophys. Acta. 612:233-244.

28. Gadek, J., G. Hunninghake, G. Fells, R. Zimmerman, and R. Crystal. 1981. Production of connective tissue-specific proteases by human alveolar macrophages is constitutive (nonregulatable). Am. Rev. Respir. Dis. 123(Suppl.):55.

29. Niederman, M. S., L. L. Fritts, W. W. Merrill, R. B. Fick, R. A. Matthay, H. Y. Reynolds, and J. B. L. Gee. 1984. Demonstration of a free elastinolytic metalloenzyme in human lung lavage fluid and its relationship to alpha ${ }_{1}$-antiprotease. Am. Rev. Respir. Dis. 129:943-947.

30. Chin, J. R., G. Murphy, and Z. Werb. 1985. Stromelysin, a connective tissue-degrading metalloendopeptidase secreted by stimulated rabbit synovial fibroblasts in parallel with collagenase. Biosynthesis, isolation, characterization, and substrates. J. Biol. Chem. 260:12367-12376.

31. Catanese, J., and L. F. Kress. 1984. Enzymatic inactivation of human plasma $\mathrm{C} \overline{1}$-inhibitor and $\alpha_{1}$-antichymotrypsin by Pseudomonas aeruginosa proteinase and elastase. Biochim. Biophys. Acta. 789:37-43.

32. Abrams, W. R., G. Weinbaum, L. Weissbach, H. Weissbach, and N. Brot. 1981. Enzymatic reduction of oxidized $\alpha$-1-proteinase inhibitor restores biological activity. Proc. Natl. Acad. Sci. USA. 78:74837486. 